\title{
СУДЕБНО-ЭКСПЕРТНАЯ ДЕЯТЕЛЬНОСТЬ
}

\section{К ВОПРОСУ ОБ ИСПОЛЬЗОВАНИИ УНИВЕРСАЛЬНОГО КОМПЛЕКСА ИЗВЛЕЧЕНИЯ СУДЕБНОЙ ИНФОРМАЦИИ (UFED) ДЛЯ ОБРАБОТКИ И АНАЛИЗА СВЕДЕНИЙ ОБ АБОНЕНТАХ И (ИЛИ) АБОНЕНТСКИХ УСТРОЙСТВАХ}

\section{Дерюгин P.A.}

Аннотация: В статье рассматриваются некоторые аспекты применения универсального комплекса извлечения судебной информации (UFED) в следственной и экспертной практике. Автор раскрывает сущуность данного аппаратного комплекса и его технические возможности, а также обосновывает необходимость его применения органами предварительного следствия. Кроме того, в исследовании ставятся вопросы, касаюшчеся процеесуального оформления результатов получения сведений об абонентах и (или) абонентских устройствах с помощью универсального комплекса извлечения судебной информации (UFED) и предлагаются пути их разрешения. В работе использован комплекс общенаучных и частно-научных методов исследования, которые включают в себя такие методы, как нормативно-логическийметод, системныйметод, синтез, анализ, дедукиия, индукиия и другие методы научно-исследовательской деятельности. Новизна исследования заключается в том, что на сегодняшний день в связи с ростом количества мобильных устройств, а также зарегистрированных абонентов, среди которых присутствуют представители преступного мира, необходим соответствуюший контроль сведений передаваемых с помощзью сотовых устройств связи. В свою очередь, анализ и обработка информацчи о соединениях между абонентами и (или) абонентскими устройствами является одним из перспективных направлений в технико-криминалистическом обеспечении расследования уголовного дела.

Ключевые слова: Следователь, судебная информация, сведения об абонентах, абонентское устройство, сотовый телефон, комплекс, процессуальное оформление, криминалистическая техника, идентификация, извлечение информации.

Одним из перспективных направлений в технико-криминалистическом обеспечении расследования уголовного дела на сегодняшний день является анализ и обработка информации о соединениях между абонентами и (или) або- нентскими устройствами. Появившаяся в июле 2010 года в Уголовно-процессуальном кодексе Российской Федерации (далее УПК РФ) статья 186.1 предоставила возможность органами расследования по судебному решению получать от 
UFED представляет собой функциональное

операторов сотовой связи необходимые сведения об абонентах, не ограничивая конституционное право граждан на тайну связи [3]. До введения вышеуказанной нормы на практике истребование данных от операторов связи вызывало определенные сложности. Так, чтобы получить информацию о соединениях между абонентами следственные органы проводили контроль и запись переговоров, выемку документов или детализацию предоставлял сам владелец мобильного устройства в рамках допроса (как приложение к протоколу данного следственного действия) [2]. Нередко следователям приходилось направлять запросы в организации связи, которые в свою очередь не всегда своевременно отвечали или предоставляли некорректную информацию. Зачастую эти проблемы объяснялись отсутствием специальных технических познаний в области телекоммуникации у лиц, осуществляющих предварительное следствие или ненадлежащим уровнем взаимодействия следователя со специальными подразделениями МВД и ФСБ России, а также с операторами сотовой связи.

Путем производства следственного действия, предусмотренного статьей 186.1 УПК РФ, можно получить сведения о дате, времени, продолжительности соединений между абонентами и (или) абонентскими устройствами (пользовательским оборудованием), номерах абонентов, других данных, позволяющих идентифицировать абонентов, а также сведения о номерах и месте расположения приемопередающих и базовых станций [4]. Кроме того, органы следствия могут использовать возможности специальной высокотехнологичной криминалистической техники, которая позволяет извлекать полную информацию из любого мобильного устройства или электронного носителя (SIM-карта, съемный диск и т.п.). К такому виду оборудования относятся универсальное устройство извлечения судебной информации (UFED - Universal Forensic Extraction Device). Указанную технологию активно применяют специалисты подраз делений Главного управления криминалистики Следственного комитета Российской Федерации. и технологически совершенное программное решение в области мобильной криминалистики. Разработало устройство компания Cellebrite мировой лидер в сфере мобильных информационных технологий. Данный комплекс позволяет высокотехнологичное извлечение информации, ее расшифровку, анализ и составление отчётов о полученных оперативных сведениях. С помощью UFED можно извлечь файловую систему, а также пароли ко всем данным (даже если они были удалены) из огромного числа устройств, включающих традиционные и обычные мобильные телефоны, смартфонов, портативных устройств GPS, планшетов и телефонов китайской сборки на основе микропроцессора. Благодаря собственному аппаратному обеспечению, встроенному аккумулятору, интуитивно понятному клиенту GUI и сенсорному экрану, UFED ускоряет процесс расследования, соответствуя требованиям криминалистических исследований мобильных устройств. UFED объединяет целый комплекс простых и эффективных в использовании приложений для следователей, которые хотят расследовать дело как можно быстрее:

- UFED Physical Analyzer - приложение, предназначенное для расшифровки и анализа данных и составления отчёта;

- UFED Phone Detective - современное приложение, позволяющее моментально идентифицировать телефон;

- UFED Reader - приложение, с помощью которого уполномоченный сотрудник может поделиться с другими полученной информацией.

UFED позволяет извлечь любой сегмент из памяти мобильного устройства и использует методы углубленного декодирования, анализа и создания отчетов. С его помощью можно получить сведения об IMEI коде ${ }^{1}$ мобильного устройства,

\footnotetext{
${ }^{1}$ IMEI - International Mobile Equipment Identifier (международный идентификатор мобильного оборудования). // Приказ Министерства информационных технологий и связи РФ от 19 февраля 2008 г. № 21 «Об утверждении Правил применения абонентских станций (абонентских радиостанций) сетей подвижной радиотелефонной связи стандарта GSM-900/1800».
} 
о SIM-карте, входящих и исходящих вызовах и SMS, MMS сообщениях, об использованном интернет трафике, включая открывавшиеся страницы, о контактах, записанных в телефонной книге и на модуле SIM-карты, обо всем содержимом памяти устройства (аудио- и видео файлы, пароли, текстовые сообщения, записи календаря, служебные данные и т.п.). Комплекс UFED открывает доступ к GPS - координатам местоположения мобильного устройства, список действий производимых с телефоном, а также к содержанию переписки в социальных сетях, осуществляемой через исследуемое мобильное устройство. Как известно, информация, хранящаяся в мобильных устройствах, имеет достаточно весомое значение для уголовного дела. Данные сведения способствуют оптимизации планирования расследования преступления, проверке следственных версий и в целом - закреплению доказательственной базы по уголовному делу, а также подтверждают факт совершения лицом преступления (например, фото или видеосъемка преступления, переписка с заказчиком убийства, SMS - сообщения с угрозами в адрес потерпевшего и т.п.) или наоборот опровергают его причастность к совершению противоправных действий [1].

Однако, остается открытой проблема процессуального оформления извлечения данных, полу- чаемых с использованием криминалистической техники. Если порядок получения информации о соединениях между абонентами и (или) абонентскими устройствами закреплен в ст. 186.1 УПК РФ, то извлечение содержательной информации (фото, видео, переписка в социальных сетях и т.п.) из мобильных устройств связи с помощью UFED законодателем не урегулировано. Так, криминалистическая техника для извлечения информации из мобильных устройств используется в рамках:

- осмотра предметов (ч. 2 ст. 176 УПК РФ);

- назначения и проведения экспертизы (компьютерно-технической);

- в ходе ОРМ (ст. 6 Федерального закона от 12.08.1995 № 144-Ф3 «Об оперативно-розыскной деятельности»;

- контроля почтовых отправлений, телеграфных и иных сообщений;

- снятия информации с технических каналов связи.

На наш взгляд, для решения данной проблемы целесообразно обобщить и унифицировать практику применения специальных криминалистических устройств для извлечения информации, содержащейся в электронных мобильных устройствах, а также разработать единый подход в процессуальном оформлении получения данных сведений.

\section{Библиография:}

1. Бурцева Е.В., Рогова И.А. Проблемы получения информации, содержащейся в электронных мобильных устройствах, с применением универсального устройства извлечения судебной информации (UFED) // Materialy X mezinarodni vedecko-prakticka konf.: Efektivni nastroje modernich ved. - 2014 (27.04.2014-05.05.2014). Dil 11. Pravni vedy Administrativa. - Praha. Publishing House «Education and Scietnce» s.r.o. C. $53-57$.

2. Дерюгин Р.А. Криминалистическое значение сведений о соединениях между абонентами и (или) абонентскими устройствами // Сборник материалов IX Международной научно-практической конференции «Научные исследования и разработки». М., 2016. C. 299-302.

3. О внесении изменений в Уголовно-процессуальный кодекс Российской Федерации: федеральный закон от 01.07.2010 № 143-Ф3. СПС «Гарант» (дата обращения 25.04.2016 г.)

4. Уголовно-процессуальный кодекс Российской Федерации. (действующая редакция). [Электронный ресурc]. - URL: http:/www.consultant.ru (дата обращения 25.04.2016 г.). 


\section{References (transliterated):}

1. Burtseva E.V., Rogova I.A. Problemy polucheniya informatsii, soderzhashcheisya v elektronnykh mobil'nykh ustroistvakh, s primeneniem universal'nogo ustroistva izvlecheniya sudebnoi informatsii (UFED) // Materialy X mezinarodni vedecko-prakticka konf.: Efektivni nastroje modernich ved. - 2014 (27.04.2014-05.05.2014). Dil 11. Pravni vedy Administrativa. - Praha. Publishing House «Education and Scietnce» s.r.o. C. 53 - 57.

2. Deryugin R.A. Kriminalisticheskoe znachenie svedenii o soedineniyakh mezhdu abonentami i (ili) abonentskimi ustroistvami // Sbornik materialov IX Mezhdunarodnoi nauchno-prakticheskoi konferentsii «Nauchnye issledovaniya i razrabotki». M., 2016. S. 299-302.

3. O vnesenii izmenenii v Ugolovno-protsessual'nyi kodeks Rossiiskoi Federatsii: federal'nyi zakon ot 01.07.2010 № 143-FZ. SPS «Garant» (data obrashcheniya 25.04.2016 g.)

4. Ugolovno-protsessual'nyi kodeks Rossiiskoi Federatsii. (deistvuyushchaya redaktsiya). [Elektronnyi resurs]. - URL: http:/www.consultant.ru (data obrashcheniya 25.04.2016 g.). 